\title{
New Approaches to Fetal Growth Restriction: The Time for Metabolomics Has Come
}

\section{Novas abordagens para a restrição de crescimento fetal: é chegada a hora da metabolômica}

\author{
Debora Farias Batista Leite ${ }^{1,2,3}$ Jose Guilherme Cecatti ${ }^{10}$ \\ ${ }^{1}$ Departament of Obstetrics and Gynecology, Faculdade de Ciências Médicas, \\ Universidade Estadual de Campinas, Campinas, São Paulo, SP, Brazil \\ 2 Department of Mother and Child Health, Universidade Federal de \\ Pernambuco, Recife, PE, Brazil \\ Address for correspondence José Guilherme Cecatti, PhD, Rua \\ Alexander Fleming 101, Cidade Universitária Zeferino Vaz, 13083- \\ 889, Campinas, SP, Brazil (e-mail: cecatti@unicamp.br).
}

${ }^{3}$ Hospital Clínico, Universidade Federal de Pernambuco, Recife, PE, Brazil

Rev Bras Ginecol Obstet 2019;41:454-462.

\author{
Abstract \\ Keywords \\ - fetal growth \\ restriction \\ - small for gestational \\ age \\ - prediction \\ metabolomics

\section{Resumo}

\section{Palavras-chave} \\ - restrição do \\ crescimento fetal \\ - pequeno para a idade \\ gestacional \\ - previsão \\ metabolômica
}

Fetal growth restriction (FGR) diagnosis is often made by fetal biometric ultrasound measurements or Doppler evaluation, but most babies are only diagnosed after birth, using the birth weight as a proxy for intrauterine development. The higher risks of neurodevelopmental delay, metabolic syndrome, and cardiovascular illness associated with FGR impose a shift on the focus during pregnancy. New methodological approaches, like metabolomics, can provide novel biomarkers for intrauterine fetal development. Recent evidence on metabolites involved with fetal growth and weight show a consistent role played by lipids (especially fatty acids), amino acids, vitamin D and folic acid. Fetal energy source and metabolism, structural functions, and nervous system functioning need further evaluations in different populations. In the near future, the establishment of a core set of outcomes for FGR studies may improve the identification of the role of each metabolite in its development. Thus, we will concretely progress with the perspective of a translational capacity of metabolomics for this condition.

O diagnóstico da restrição do crescimento fetal (RCF) é frequentemente feito por medidas biométricas ultrassonográficas ou por avaliação pela Dopplervelocimetria, mas, na maioria dos casos, o diagnóstico é apenas pós-natal, usando o peso ao nascimento como um marcador para o desenvolvimento intrauterino. Riscos maiores de atraso do neurodesenvolvimento, síndrome metabólica e doenças cardiovasculares associadas com a RCF impõem uma mudança no foco durante a gestação. Novas abordagens metodológicas, como a metabolômica, podem fornecer novos biomarcadores para o desenvolvimento fetal intrauterino. As evidências recentes sobre os metabolitos envolvidos com o crescimento e peso fetal mostram um papel consistente desempenhado pelos lipídios (especialmente os ácidos graxos), aminoácidos, vitamina

DJose Guilherme Cecatti's ORCID is https://orcid.org/0000-00031285-8445.

received January 26, 2019 accepted April 16, 2019
DOI https://doi.org/ 10.1055/s-0039-1692126. ISSN 0100-7203.
Copyright $\odot 2019$ by Thieme Revinter Publicações Ltda, Rio de Janeiro, Brazil
License terms

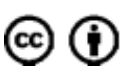


D e ácido fólico. A fonte de energia fetal e seu metabolismo, a função estrutural e o funcionamento do sistema nervoso devem ser detalhadamente investigados nos próximos estudos de validação. Em breve, o estabelecimento de um conjunto de desfechos a serem descritos para os estudos de RCF pode melhorar a identificação do papel de cada metabolito no seu desenvolvimento. Assim, iremos progredir no entendimento da RCF numa perspectiva da capacidade translacional da metabolômica para este transtorno.

\section{Introduction}

The impairment of fetal growth has gained major importance over the past few years. There is an increasing body of evidence suggesting that long-term health outcomes could be managed still during pregnancy. Findings among children $^{1}$ and adults ${ }^{2-4}$ who were born with a birth weight (BW) below average or who were exposed to maternal undernutrition in utero ${ }^{5,6}$ support the hypothesis of the developmental origins of health and disease (DOHaD). Fetal growth restriction (FGR; or intrauterine growth restriction, IUGR), that is, when the fetus does not reach its 'optimal' growth potential, is possibly the underlying condition of future epidemiological burden of noncommunicable chronic diseases (NCDs).

Fetal growth restriction was recognized as a distinct condition in perinatology only in the $1960 \mathrm{~s},{ }^{7}$ and it is usually defined by estimated fetal weight $(\mathrm{EFW})<10^{\text {th }}$ centile or fetal abdominal circumference $<10^{\text {th }}$ centile. ${ }^{8}$ Considering the postnatal growth as a development continuum that begins in intrauterine life, BW can be used as a measurement of fetal growth. ${ }^{9}$ Then, FGR (or IUGR) can describe fetal growth impairment of any severity, confirmed at birth or not, ${ }^{10-14}$ while small for gestational age (SGA) neonates can define either FGR or constitutionally small infants. ${ }^{13-15}$ However, and unfortunately, there is still little consensus, both from the obstetrics and neonatology standpoints, regarding how clinicians should screen, diagnose and manage these fetuses and newborns. In fact, FGR is responsible for half of the rate of stillbirths, ${ }^{16}$ and the odds of neonatal mortality can be as high as 3.91 (95\% confidence interval [95\%CI]: 3.21-4.76). ${ }^{17}$ Still, suspicion of fetal growth impairment in pregnancy clearly improves perinatal outcomes. ${ }^{18}$ Clinical factors, ultrasound scan (US) parameters or placental biomarkers have shown modest clues about FGR pathophysiology and management.

Therefore, the development of new strategies for FGR and SGA evaluation is necessary. The postgenomic era is marked by rapid advances in the so-called omics sciences, including transcriptomics (the analysis of messenger ribonucleic acid [mRNA]), proteomics (the analysis of proteins) and metabolomics. ${ }^{19}$ The latter is dedicated to studying metabolites, small molecules between 50 and 2,000 Daltons, which represent the complex interaction between each individual and the environment. ${ }^{19,20}$ With metabolomic platforms, it is possible to evaluate endogenous compounds or exposure to contaminants, for instance, and to offer personalized care based on disease phenotype. In pregnancy, it is still an open field to appraise maternal and fetal adaptive responses to the intrauterine environment.

Metabolomic studies have shown maternal metabolic changes during normal pregnancies ${ }^{21,22}$ and how BW is determined; ${ }^{23,24}$ they soon emerged as a promising predictive and diagnostic tool for preeclampsia. ${ }^{25}$ We hypothesize that recent advances in FGR evaluation have at least a similar potential. Therefore, the aims of the present review are to summarize the investigations of FGR with a metabolomic approach, and the future perspectives of translating this knowledge to the bedside practice.

\section{What are Metabolomics and its Application on Obstetrics?}

The first mention of the term 'metabolome' occurred in $1998,{ }^{26}$ and much has been done since then. The metabolome is dynamic by nature, and represents a meaningful simultaneous evaluation of genetic and environmental influences. ${ }^{27}$ As FGR is a heterogeneous syndrome and appears to be a metabolic disorder, both for the mother and the fetus, metabolomics is thought to be the best approach to investigate it.

Nuclear magnetic resonance (NMR) and mass spectrometry (MS) are the most common analytical platforms applied; MS can be coupled with liquid or gas chromatography, for example (Dunn et al $^{27}$ provide a comprehensive review on this issue). Two main types of investigations can be made, with different objectives: untargeted or targeted. The first one, untargeted or 'metabolic profiling,' evaluates simultaneously thousands of metabolites in a given sample. ${ }^{19}$ After careful bioinformatics data analysis (principal component analysis [PCA], or partial least squares discriminant analysis [PLS-DA], for example), the peaks must be matched by retention time, accurate mass and spectra. The Human Metabolome Database (www.hmdb.ca) is an example of repository in which the chemical taxonomy (chemical superclass and class, for example) and known biological processes are listed and can be consulted freely. ${ }^{28}$ Metabolic pathways can be checked at the Kyoto Encyclopedia of Genes and Genomes (www.genome.jp/kegg), for example. With untargeted analysis, it is not possible to determine the absolute quantities of compounds, but a relative change between groups. Then, they are generally applied for hypothesis-generating purposes, attempting to comprehend biological processes. ${ }^{20,27}$ In sequence, they should be validated in large-scale studies. ${ }^{27}$ 
On the other hand, a targeted analysis is hypothesisdriven, that is, devoted to measuring prespecified biomarkers, ${ }^{19,27}$ with acceptable accuracy measurements (sensitivity, specificity, and area under the receiver operating curve [AUC], for example) to differentiate health conditions. ${ }^{20}$ In the latter case, a predictive, diagnostic or prognostic model can be elaborated with as many metabolites as necessary. ${ }^{20}$ Sample preparation will ultimately depend on study design and type of biological sample chosen. ${ }^{27}$ However, it is important to note that biomarkers developed for a given population are only suitable for that population..$^{20}$ Therefore, well-delineated metabolomic research in perinatal medicine has the potential to answer relevant gaps in the clinical practice.

Fetal metabolism depends on the interaction of the fetus with the maternal organism, and it is mediated at the placental level. There probably is a trend towards higher levels of nonessential amino acids (that is, those synthesized by human cells) with increasing gestational age in maternal blood, ${ }^{21}$ while they show downregulated levels in maternal hair. ${ }^{22}$ Some metabolic pathways are suspected to influence $\mathrm{BW}$, such as the carnitine shuttle, de novo fatty acid biosynthesis, 21-carbon (C-21) steroid biosynthesis and metabolism, prostaglandin formation, and glycerophospholipid, glycosphingolipid and tryptophan pathways. ${ }^{23,24}$ Ultimately, these metabolites are involved with energy generation, oxidation of fatty acids, ${ }^{29}$ immune functions, ${ }^{30}$ and cellmembrane organization. ${ }^{31}$ At the same time, environmental exposure to organochlorine compounds, such as phthalate metabolites and perfluorooctanoic acid, are associated to a decrease in $\mathrm{BW},{ }^{32}$ in a sex-specific manner. ${ }^{33}$

It is known that normal pregnancies show metabolic disruption when submitted to any pathological condition, such as fetal chromosomal abnormalities (upregulation of acetone in maternal urine, for example $)^{34}$; hypertensive disorders (downregulation of acetate in maternal urine, for example) ${ }^{34}$; gestational diabetes mellitus (downregulated levels of 2-oxobutyric acid, for example) ${ }^{22}$; restriction of growth, or any combination of those factors. ${ }^{35}$ Changes can be detected in any biological sample, such as blood, urine, hair or even breastmilk. ${ }^{36}$ However, the main difficulty for conducting and interpreting metabolomic studies in reproductive medicine is the significant variety of definitions. For FGR, EFW by US, ${ }^{11,37}$ uterine or umbilical artery blood flow abnormalities, ${ }^{14}$ or $\mathrm{BW}^{10,12,15,38,39}$ are all criteria applied to identify these fetuses and newborns. Although not consensual, they represent important FGR phenotypes in the clinical practice. Then, in order to offer a deeper evaluation of the available knowledge, we have kept the definitions applied by each study and present the most recent findings on metabolomic studies with mothers and newborns, near delivery.

\section{What Metabolomics has Found in Growth- Restricted Fetuses and Newborns}

Maternal blood, urine, and hair have been explored for FGR evaluation with metabolomics, as well as amniotic fluid, venous cord blood, and newborn urine. In pregnancy, some studies have associated maternal levels of certain metabolites with BW. Our group has recently suggested a disruption of lipid metabolism in the $2^{\text {nd }}$ trimester of SGA pregnancies (BW $<10^{\text {th }}$ centile). ${ }^{40}$ Untargeted analyses of maternal blood ${ }^{15}$ and hair ${ }^{22,41}$ have provided reliable predictive accuracy that should be validated in different settings. In the third trimester, there is major deposition of fat in fetal tissues and in the brain, which has led to some investigations on maternal fatty acid metabolism. Between 26-28w, linoleic acid levels are positively associated with BW and abdominal adipose tissue volume, while docosahexaenoic acid is related to the proportionality of growth (length/height). ${ }^{42}$ Near delivery, the mother/newborn ratio of medium-chain fatty acids is downregulated in pregnancies affected by IUGR with Doppler abnormalities, ${ }^{14}$ suggesting the increased need of energetic and structural metabolites by these newborns.

Most metabolomic studies with newborns have focused on samples collected near delivery, to get the closest snapshot of fetal metabolism. The findings from neonatal and maternal metabolomic investigations are summarized in -Tables $\mathbf{1}$ and $\mathbf{2}$.

Favretto et $\mathrm{al}^{11}$ found 22 metabolites that could differentiate adequate for gestational age (AGA) newborns from newborns with FGR (suspected during pregnancy and confirmed after birth, both EFW and BW $<10^{\text {th }}$ centile). A total of seven were alpha-aminoacids (that is, those involved with protein synthesis), and all compounds were upregulated in FGR newborns. Tryptophan, phenylalanine, and glutamate individually had the best accuracy, reaching $100 \%$ of sensitivity (the former two compounds) and at least $85 \%$ of specificity (the latter one). ${ }^{11}$ However, in the newborns sampled by Sanz-Cortés et al, ${ }^{12}$ amino acids were only significant in late-onset IUGR ( $B W<10^{\text {th }}$ centile with delivery $>35 \mathrm{w}$ and normal Doppler evaluation). On the other hand, Liu et $\mathrm{al}^{39}$ searched for amino acids and acylcarnitines in neonatal blood. Homocysteine, methionine, tyrosine, alanine, ornithine, and serine showed decreased levels in IUGR $<3^{\text {rd }}$ centile of BW. ${ }^{39}$ While ornithine can be involved with cell proliferation, differentiation and apoptosis, ${ }^{43}$ serine acts as a neurotransmitter of glutamate $\mathrm{N}$-methyl-D-aspartate (NMDA) receptors in brain. ${ }^{44}$ Interestingly, the last two amino acids were upregulated in SGA children without catch-up growth. ${ }^{45}$

In neonatal urine, Dessí et al ${ }^{10,38}$ and Barberini et $\mathrm{al}^{37}$ found increased levels of myo-inositol in FGR cases (both EFW and $\mathrm{BW}<10^{\text {th }}$ centile). Myo-inositol belongs to the alcohol and polyols chemical subclass. ${ }^{28}$ In adipose cells, it downregulates the release of free fatty acids, and on the ovaries, it mediates glucose uptake and follicle stimulating hormone (FSH) signaling. ${ }^{46}$ Unfortunately, Barberini et al ${ }^{37}$ grouped SGA and large for gestational age (LGA) newborns for a final comparison, but there is some evidence pointing to a higher risk of metabolic events later in life in both groups $2,3,47,48$ of newborns. Interestingly, myo-inositol has been used for the treatment of polycystic ovary syndrome, ${ }^{46}$ which has a known relationship with metabolic syndrome. Thus, more research is needed to elucidate which pathways are affected in SGA and LGA. 


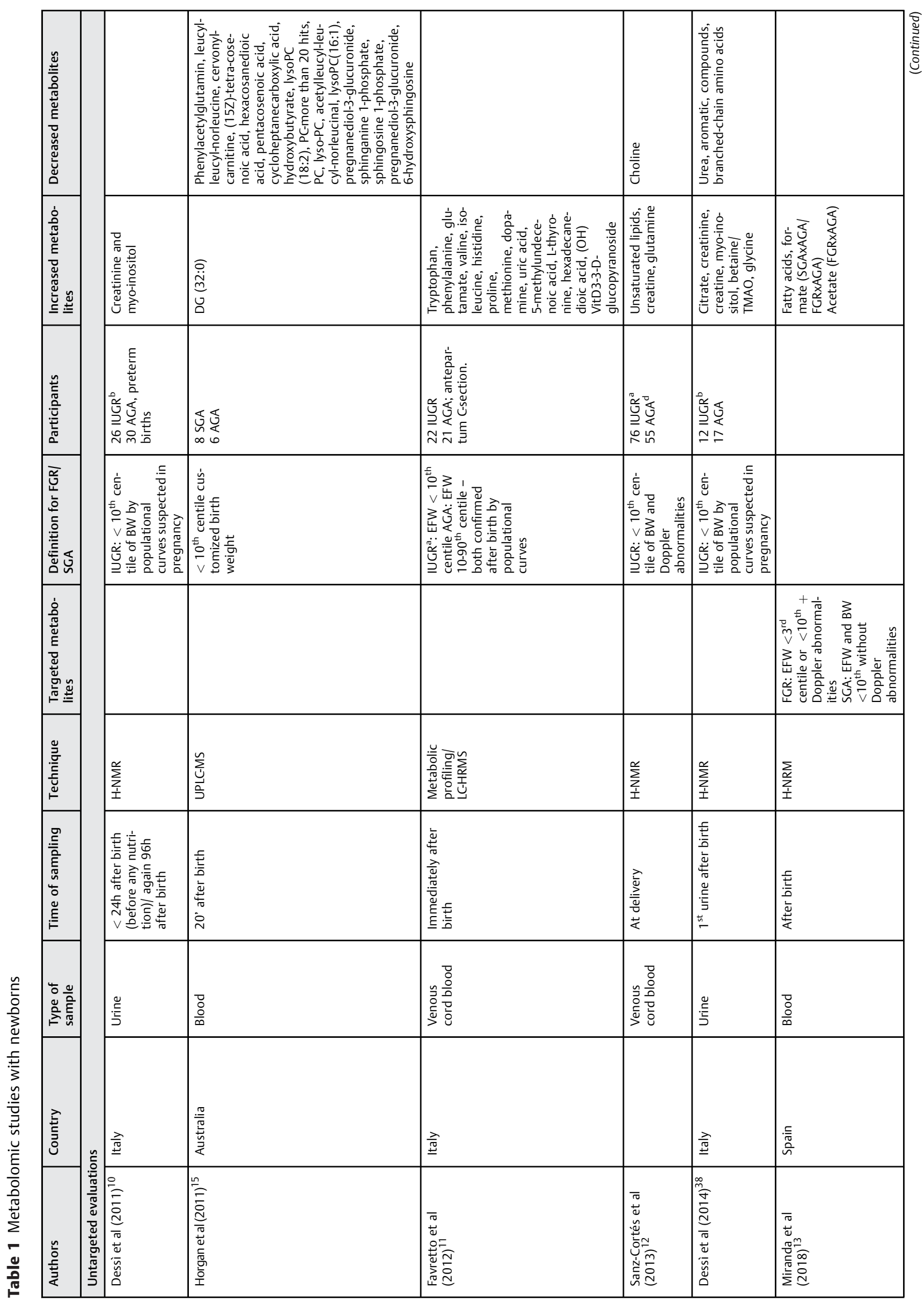



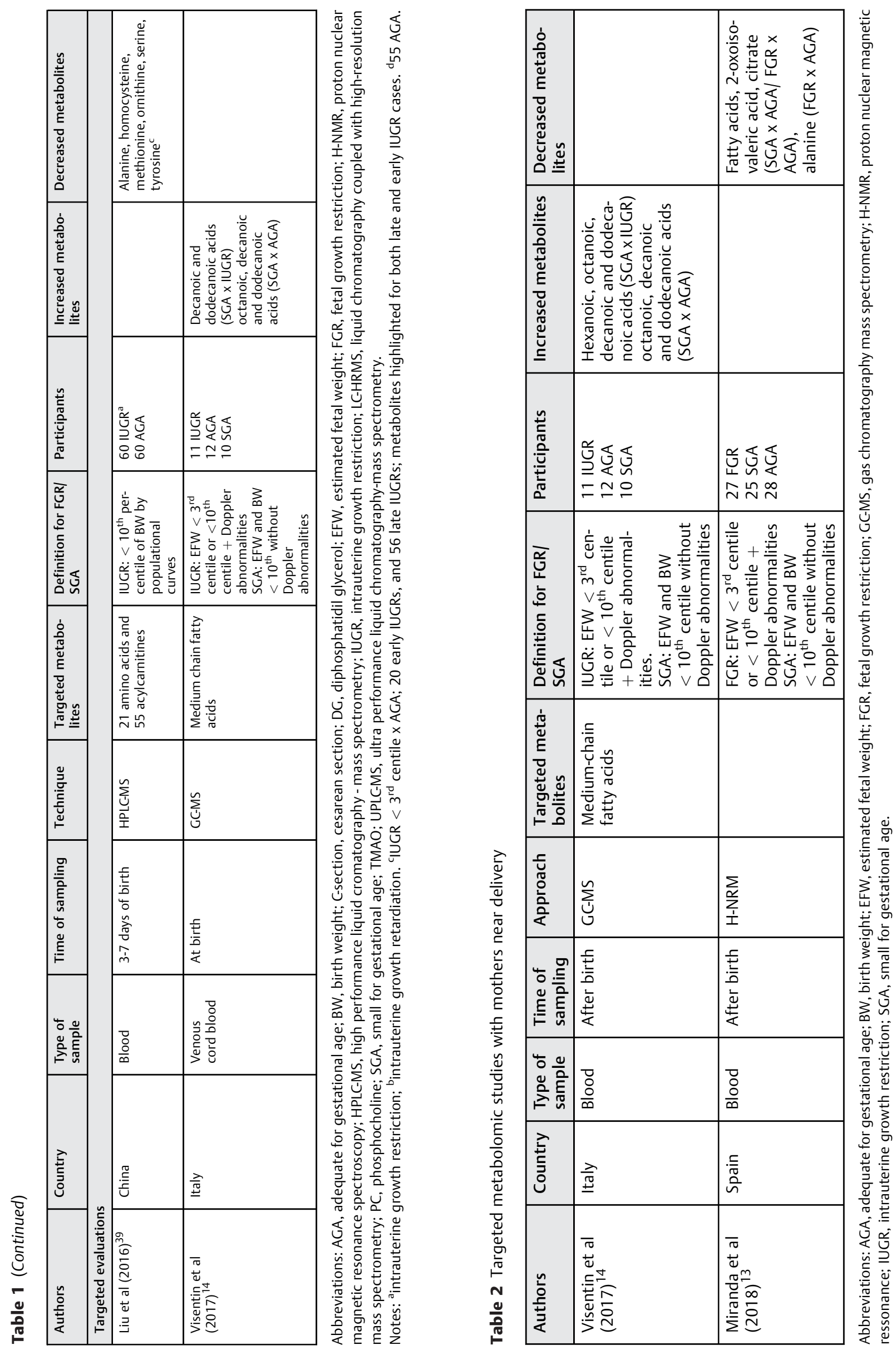
Vitamin D has been involved in a multiplicity of biological pathways. It regulates calcium transport through the placenta and parathyroid hormone levels, which may play a role in fetal skeletal development. ${ }^{49}$ Liquid chromatography coupled to MS is the best approach to measure vitamin D levels. Evidence from trials suggest a protective effect of maternal supplementation of vitamin $\mathrm{D}$ on $\mathrm{BW},{ }^{50}$ but less is known about its direct impacts on BW or its implications regarding SGA pathogenesis, if there are any. Vitamin D concentration indeed varies according to ethnicity and smoking patterns, ${ }^{51}$ variables already associated with impaired fetal growth. In the $1^{\text {st }}$ trimester, vitamin D levels $<50 \mathrm{nmol} / \mathrm{L}$ were statistically associated with SGA (BW $<5^{\text {th }}$ centile) infants. ${ }^{52}$ In the $2^{\text {nd }}$ trimester of women with high risk for preeclampsia, vitamin D levels $\geq 75 \mathrm{nmol} / \mathrm{L}$ were associated with decreased risk for $\mathrm{BW}<10^{\text {th }}$ centile (adjusted risk ratio, [aRR]: 0.46; 95\% confidence interval [95\%CI]: 0.24-0.87). ${ }^{53}$ However, in low-risk women, levels $<30 \mathrm{nmol} / \mathrm{L}$ at $15 \mathrm{w}$ were not associated with SGA (BW $<10^{\text {th }}$ centile), ${ }^{54}$ even when there were increased parathyroid hormone levels. ${ }^{55}$ These findings suggest that the thresholds of vitamin $\mathrm{D}$ that confer either a risk or a protective effect are not the same as those used in the clinical practice to define normal levels in pregnancy. Indeed, apart from the high prevalence of vitamin D deficiency in pregnancy and in cord blood, it appears to have no impact on infant musculoskeletal development at $2 y^{51}$

This raises the question of whether there is constitutional or truly impaired fetal growth regarding BW. Some researchers have investigated differences between newborns with BW $<10^{\text {th }}$ with or without Doppler abnormalities. ${ }^{14}$ As a matter of fact, metabolic differences are understandable, and perhaps expected, due to fetal blood flow redistribution. Visentin et $\mathrm{al}^{14}$ found lower levels of decanoic and dodecanoic acids in FGR (EFW $<3^{\text {rd }}$ centile or $<10^{\text {th }}$ centile plus Doppler alterations) compared to SGA (EFW and BW $<10^{\text {th }}$ without maternal or fetal hemodynamic abnormalities) in both newborns and their mothers. Capric and lauric acids respectively are involved with unsaturated fatty acid biosynthesis, some of them prostaglandin precursors (linoleic acid, for example). ${ }^{29}$ In normal pregnancies, they represent an additional fetal energy source through ketogenesis. ${ }^{21}$ Thus, one could suggest a higher maternal transfer of these nonesterified acids in FGR pregnancies, besides higher fetal use of ketone bodies (energy and structural roles).

In monochorionic twin pregnancies, for instance, amino acid pathways appear to be disrupted in pairs with discordant growth. Cosmi et al ${ }^{56}$ compared FGR (EFW $<10^{\text {th }}$ centile plus abnormal Doppler) infants with AGA infants (EFW $>10^{\text {th }}$ centile, normal Doppler waveforms) from the same index pregnancy. They found downregulated levels of valine, isoleucine (essential branched-chain amino acids), proline and tryptophan (nonessential branched-chain amino acids): proline is part of the composition of collagen, while tryptophan degradation leads to redox cofactors. ${ }^{30}$ At the same time, there was an upregulation of phenylalanine (an essential branchedchain amino acid; precursor of catecholamine neurotransmitters). ${ }^{28}$ These findings need further consideration, but already highlight a metabolic shift in FGR pregnancies.
Ultimately, discriminating the 'truly restricted fetuses' from the 'constitutionally small' ones may require more than a BW evaluation. From a clinical point of view, it should at least include adverse perinatal outcomes. At the same time, from a translational point of view, this is a great field for advancements with metabolomic studies in a shorter period.

\section{What Should Be Explored}

The World Health Organization (WHO) now recommends iron and folic acid (at least $400 \mathrm{mcg}$ ) supplementation throughout pregnancy. ${ }^{57}$ Apart from its role in preventing neural tube defects, epidemiological data indicate folate participation on BW. For instance, its depletion is suspected to justify the repeated SGA in case of interpregnancy intervals lower than 23 months. ${ }^{58}$ In fact, a recent systematic review $^{59}$ has pointed that folic acid supplementation before conception decreases the risk of SGA $<10^{\text {th }}$ centile BW (adjusted odds ratio [aOR]: $0.80 ; 95 \% \mathrm{CI}: 0.71-0.90)$ or $<5^{\text {th }}$ centile BW (aOR: 0.78; 95\%CI: 0.66-0.91). ${ }^{59}$ Additionally, at the nuclei level, folate acts as a methyl donor, and little is known about its involvement with the methylated enriched pathways observed in SGA pregnancies, if there is any. ${ }^{60}$ Therefore, whether folic acid or homocysteine mediate FGR pathogenesis or are only biomarkers of disease merits consideration in further metabolomic researches.

Amino acid supplementation to improve fetal weight is another intriguing relationship. L-arginine is a precursor of nitric oxide, which regulates placental perfusion. Arginine in amniotic fluid is directly correlated with BW, body length and head circumference. ${ }^{61}$ Evidence from small trials show a marked increase in BW (mean difference: 0.41; 95\%CI: 0.24-0.58), although the characteristics and follow-up of the participants, as well as the route and duration of arginine supplementation, were heterogeneous. ${ }^{62}$ Arginine is an essential amino acid for infants, and evidence from experimental data suggests its role in inducing protein synthesis that is not dependent on nitric oxide pathways. $^{63}$ Fetal growth restriction placental explants in hypoxic $\left(\mathrm{O}_{2} 1 \%\right)$ conditions have half of the metabolites in common with AGA pregnancies under normal oxygen tension $\left(\mathrm{O}_{2} 6 \%\right)$, suggesting that hypoxia would play a role in FGR pathogenesis.

As metabolomics is a very sensitive and holistic approach, extra care must be taken regarding sample selection. Evaluating pregnant women or newborns different from those found in the clinical practice will limit the translational potential of this technology. Although guidelines for reporting observational epidemiologic ${ }^{64}$ or metabolomic ${ }^{65}$ studies are available, they do not fulfill the necessary details for translational investigations. Meaningful transfer of the bedside advancements to the clinical practice is a real concern and will be achieved only if researchers and clinicians speak the same language. In the near future, the establishment of a core set of outcomes for FGR studies may organize a description of clinical data and prevent duplicate efforts. Then, we believe that concrete progress with metabolomics will advance faster. 


\section{Conclusion}

Metabolomics is a novel and promising area of research in reproductive medicine. Although some results may contradict each other, the maternal and fetal metabolisms are highly dynamic, and may adapt according to several influences. Levels of metabolites in cord blood might represent increased fetal demands or catabolism, for instance. The current available knowledge points to a disruption in fetal energy source and metabolism, structural functions (cell surface membrane, cell proliferation and apoptosis), and nervous system functioning (neurotransmitter pathways). Future validations of metabolomic studies ${ }^{20}$ in different populations will set the ideal thresholds for the clinical practice. Similarly, metabolomic findings may offer clues about FGR prevention (primary up to tertiary) and treatment. At the end, we envision the possible distinction of fetuses that reach 'optimal growth' from others that do not.

\section{Conflicts of Interest}

The authors have none to declare.

\section{Acknowledgments}

DFBL was supported by the Brazilian Federal Agency for Support and Evaluation of Higher Education Professionals (CAPES, in the Portuguese acronym; process number 88881.134512/2016-01) during her twinning Ph.D. program at the University College Cork (Cork, Ireland). CAPES had no role in the authors' decision to draft or submit the present manuscript. We are grateful to Professors Renato Passini Júnior and Maria Laura Costa for their kind notes to this manuscript.

\section{References}

1 Meher S, Hernandez-Andrade E, Basheer SN, Lees C. Impact of cerebral redistribution on neurodevelopmental outcome in small-for-gestational-age or growth-restricted babies: a systematic review. Ultrasound Obstet Gynecol 2015;46(04):398-404. Doi: $10.1002 /$ uog. 14818

2 Barker DJ, Osmond C, Simmonds SJ, Wield GA. The relation of small head circumference and thinness at birth to death from cardiovascular disease in adult life. BMJ 1993;306(6875):422-426. Doi: 10.1136/bmj.306.6875.422

3 Prioreschi A, Munthali RJ, Kagura J, et al. The associations between adult body composition and abdominal adiposity outcomes, and relative weight gain and linear growth from birth to age 22 in the Birth to Twenty Plus cohort, South Africa. PLoS One 2018;13(01): e0190483. Doi: 10.1371/journal.pone.0190483

4 Araújo de França GV, Restrepo-Méndez MC, Loret de Mola C, Victora CG. Size at birth and abdominal adiposity in adults: a systematic review and meta-analysis. Obes Rev 2014;15(02): 77-91. Doi: 10.1111/obr.12109

5 Wang $\mathrm{N}$, Wang X, Li Q et al. The famine exposure in early life and metabolic syndrome in adulthood. Clin Nutr 2017;36(01): 253-259. Doi: 10.1016/j.clnu.2015.11.010

6 Roseboom TJ, Painter RC, van Abeelen AFM, Veenendaal MVE, de Rooij SR. Hungry in the womb: what are the consequences? Lessons from the Dutch famine. Maturitas 2011;70(02): 141-145. Doi: 10.1016/j.maturitas.2011.06.017

7 Warkany J, Monroe BB, Sutherland BS. Intrauterine growth retardation. Am J Dis Child 1961;102:249-279
8 McCowan LM, Figueras F, Anderson NH. Evidence-based national guidelines for the management of suspected fetal growth restriction: comparison, consensus, and controversy. Am J Obstet Gynecol 2018;218(2S):S855-S868. Doi: 10.1016/j.ajog.2017.12.004

9 Lubchenco LO, Hansman C, Dressler M, Boyd E. Intrauterine growth as estimated from liveborn birth-weight data at 24 to 42 weeks of gestation. Pediatrics 1963;32:793-800

10 Dessì A, Atzori L, Noto A, et al. Metabolomics in newborns with intrauterine growth retardation (IUGR): urine reveals markers of metabolic syndrome. J Matern Fetal Neonatal Med 2011;24 (Suppl 2):35-39. Doi: 10.3109/14767058.2011.605868

11 Favretto D, Cosmi E, Ragazzi E, et al. Cord blood metabolomic profiling in intrauterine growth restriction. Anal Bioanal Chem 2012;402(03):1109-1121. Doi: 10.1007/s00216-011-5540-z

12 Sanz-Cortés M, Carbajo RJ, Crispi F, Figueras F, Pineda-Lucena A, Gratacós E. Metabolomic profile of umbilical cord blood plasma from early and late intrauterine growth restricted (IUGR) neonates with and without signs of brain vasodilation. PLoS One 2013;8(12):e80121. Doi: 10.1371/journal.pone.0080121

13 Miranda J, Simões RV, Paules C, et al. Metabolic profiling and targeted lipidomics reveals a disturbed lipid profile in mothers and fetuses with intrauterine growth restriction. Sci Rep 2018;8 (01):13614. Doi: 10.1038/s41598-018-31832-5

14 Visentin S, Crotti S, Donazzolo E, et al. Medium chain fatty acids in intrauterine growth restricted and small for gestational age pregnancies. Metabolomics 2017;13(05):1-9. Doi: 10.1007/s11306017-1197-8

15 Horgan RP, Broadhurst DI, Walsh SK, et al. Metabolic profiling uncovers a phenotypic signature of small for gestational age in early pregnancy. J Proteome Res 2011;10(08):3660-3673. Doi: $10.1021 /$ pr2002897

16 Chou D, Daelmans B, Jolivet RR, Kinney M, Say L; Every Newborn Action Plan (ENAP) and Ending Preventable Maternal Mortality (EPMM) working groups. Ending preventable maternal and newborn mortality and stillbirths. BMJ 2015;351:h4255. Doi: 10.1136/ bmj.h4255

17 Mendez-Figueroa H, Chauhan SP, Barrett T, Truong VTT, Pedroza C, Blackwell SC. Population versus customized growth curves: prediction of composite neonatal morbidity. Am J Perinatol 2018; •..; Doi: 10.1055/s-0038-1675161

18 Lindqvist PG, Molin J. Does antenatal identification of small-forgestational age fetuses significantly improve their outcome? Ultrasound Obstet Gynecol 2005;25(03):258-264. Doi: 10.1002/ uog.1806

19 Patti GJ, Yanes O, Siuzdak G. Innovation: Metabolomics: the apogee of the omics trilogy. Nat Rev Mol Cell Biol 2012;13(04): 263-269. Doi: $10.1038 / \mathrm{nrm} 3314$

20 Xia J, Broadhurst DI, Wilson M, Wishart DS. Translational biomarker discovery in clinical metabolomics: an introductory tutorial. Metabolomics 2013;9(02):280-299. Doi: 10.1007/ s11306-012-0482-9

21 Lindsay KL, Hellmuth C, Uhl O, et al. Longitudinal metabolomic profiling of amino acids and lipids across healthy pregnancy. PLoS One 2015;10(12):e0145794. Doi: 10.1371/journal.pone.0145794

22 Delplancke TDJ, de Seymour JV, Tong C, et al. Analysis of sequential hair segments reflects changes in the metabolome across the trimesters of pregnancy. Sci Rep 2018;8(01):36. Doi: 10.1038/ s41598-017-18317-7

23 Robinson O, Keski-Rahkonen P, Chatzi L, et al. Cord blood metabolic signatures of birth weight: a population-based study. J Proteome Res 2018;17(03):1235-1247. Doi: 10.1021/acs. jproteome.7b00846

24 Lu YP, Reichetzeder C, Prehn C, et al. Cord blood lysophosphatidylcholine $16: 1$ is positively associated with birth weight. Cell Physiol Biochem 2018;45(02):614-624. Doi: 10.1159/000487118

25 McKeating DR, Fisher JJ, Perkins AV. Elemental metabolomics and pregnancy outcomes. Nutrients 2019;11(01):E73. Doi: 10.3390/ nu11010073 
26 Oliver SG, Winson MK, Kell DB, Baganz F. Systematic functional analysis of the yeast genome. Trends Biotechnol 1998;16(09): 373-378. Doi: 10.1016/S0167-7799(98)01214-1

27 Dunn WB, Broadhurst DI, Atherton HJ, Goodacre R, Griffin JL. Systems level studies of mammalian metabolomes: the roles of mass spectrometry and nuclear magnetic resonance spectroscopy. Chem Soc Rev 2011;40(01):387-426. Doi: 10.1039/b906712b

28 Wishart DS, Feunang YD, Marcu A, et al. HMDB 4.0: the human metabolome database for 2018. Nucleic Acids Res 2018;46(D1): D608-D617. Doi: 10.1093/nar/gkx1089

29 Longo N, Frigeni M, Pasquali M. Carnitine transport and fatty acid oxidation. Biochim Biophys Acta 2016;1863(10):2422-2435. Doi: 10.1016/j.bbamcr.2016.01.023

30 Badawy AAB. Kynurenine pathway of tryptophan metabolism: regulatory and functional aspects. Int J Tryptophan Res 2017; 10:1-20. Doi: 10.1177/1178646917691938

31 Lingwood CA. Glycosphingolipid functions. Cold Spring Harb Perspect Biol 2011;3(07):a004788. Doi: 10.1101/cshperspect.a004788

32 Lenters V, Portengen L, Rignell-Hydbom A, et al. Prenatal phthalate, perfluoroalkyl acid, and organochlorine exposures and term birth weight in three birth cohorts: multi-pollutant models based on elastic net regression. Environ Health Perspect 2016;124(03): 365-372. Doi: 10.1289/ehp.1408933

33 Wang Y, Adgent M, Su PH, et al. Prenatal exposure to perfluorocarboxylic acids (PFCAs) and fetal and postnatal growth in the Taiwan maternal and infant cohort study. Environ Health Perspect 2016;124(11):1794-1800. Doi: 10.1289/ehp.1509998

34 Diaz SO, Barros AS, Goodfellow BJ, et al. Second trimester maternal urine for the diagnosis of trisomy 21 and prediction of poor pregnancy outcomes. J Proteome Res 2013;12(06):2946-2957. Doi: $10.1021 / \mathrm{pr} 4002355$

35 Heazell AEP, Bernatavicius G, Warrander L, Brown MC, Dunn WB. A metabolomic approach identifies differences in maternal serum in third trimester pregnancies that end in poor perinatal outcome. Reprod Sci 2012;19(08):863-875. Doi: 10.1177/ 1933719112438446

36 Bobiński R, Mikulska M, Mojska H, Simon M. Comparison of the fatty acid composition of transitional and mature milk of mothers who delivered healthy full-term babies, preterm babies and fullterm small for gestational age infants. Eur J Clin Nutr 2013;67(09): 966-971. Doi: 10.1038/ejcn.2013.96

37 Barberini L, Noto A, Fattuoni C, et al. Urinary metabolomics (GCMS) reveals that low and high birth weight infants share elevated inositol concentrations at birth. J Matern Fetal Neonatal Med 2014;27(Suppl 2):20-26. Doi: 10.3109/14767058.2014.954786

38 Dessì A, Marincola FC, Pattumelli MG, et al. Investigation of the ${ }^{1} \mathrm{H}-\mathrm{NMR}$ based urine metabolomic profiles of IUGR, LGA and AGA newborns on the first day of life. J Matern Fetal Neonatal Med 2014;27(Suppl 2):13-19. Doi: 10.3109/14767058.2014.955674

39 Liu J, Chen XX, Li XW, Fu W, Zhang WQ. Metabolomic research on newborn infants with intrauterine growth restriction. Medicine (Baltimore) 2016;95(17):e3564. Doi: 10.1097/ MD.0000000000003564

40 Leite DFB, Morillon AC, Melo Júnior EF, et al. Metabolomics for predicting fetal growth restriction: protocol for a systematic review and meta-analysis. BMJ Open 2018;8(12):e022743. Doi: 10.1136/bmjopen-2018-022743

41 Sulek K, Han TL, Villas-Boas SG, et al. Hair metabolomics: identification of fetal compromise provides proof of concept for biomarker discovery. Theranostics 2014;4(09):953-959. Doi: $10.7150 /$ thno.9265

42 Bernard JY, Tint MT, Aris IM, et al. Maternal plasma phosphatidylcholine polyunsaturated fatty acids during pregnancy and offspring growth and adiposity. Prostaglandins Leukot Essent Fatty Acids 2017;121:21-29. Doi: 10.1016/j.plefa.2017.05.006

43 Sivashanmugam MJ J, v U, K N S. Ornithine and its role in metabolic diseases: An appraisal. Biomed Pharmacother 2017; 86:185-194. Doi: 10.1016/j.biopha.2016.12.024
44 Montesinos Guevara C, Mani AR. The role of D-serine in peripheral tissues. Eur J Pharmacol 2016;780:216-223. Doi: 10.1016/j. ejphar.2016.03.054

45 Murray PG, Butcher I, Dunn WB, et al. Metabolites involved in glycolysis and amino acid metabolism are altered in short children born small for gestational age. Pediatr Res 2016;80(02): 299-305. Doi: 10.1038/pr.2016.72

46 Unfer V, Facchinetti F, Orrù B, Giordani B, Nestler J. Myo-inositol effects in women with PCOS: a meta-analysis of randomized controlled trials. Endocr Connect 2017;6(08):647-658. Doi: 10.1530/ec-17-0243

47 Evagelidou EN, Giapros VI, Challa AS, Kiortsis DN, Tsatsoulis AA, Andronikou SK. Serum adiponectin levels, insulin resistance, and lipid profile in children born small for gestational age are affected by the severity of growth retardation at birth. Eur J Endocrinol 2007;156(02):271-277. Doi: 10.1530/eje.1.02337

48 Evagelidou EN, Giapros VI, Challa AS, et al. Prothrombotic state, cardiovascular, and metabolic syndrome risk factors in prepubertal children born large for gestational age. Diabetes Care 2010; 33(11):2468-2470. Doi: 10.2337/dc10-1190

49 Agarwal S, Kovilam O, Agrawal DK. Vitamin D and its impact on maternal-fetal outcomes in pregnancy: A critical review. Crit Rev Food Sci Nutr 2018;58(05):755-769. Doi: 10.1080/ 10408398.2016.1220915

50 Bi WG, Nuyt AM, Weiler H, Leduc L, Santamaria C, Wei SQ. Association between Vitamin D supplementation during pregnancy and offspring growth, morbidity, and mortality: a systematic review and meta-analysis. JAMA Pediatr 2018;172(07): 635-645. Doi: 10.1001/jamapediatrics.2018.0302

51 Kiely M, O'Donovan SM, Kenny LC, Hourihane JOB, Irvine AD, Murray DM. Vitamin D metabolite concentrations in umbilical cord blood serum and associations with clinical characteristics in a large prospective mother-infant cohort in Ireland. J Steroid Biochem Mol Biol 2017;167:162-168. Doi: 10.1016/j. jsbmb.2016.12.006

52 Ertl R, Yu CKH, Samaha R, Akolekar R, Nicolaides KH. Maternal serum vitamin $D$ at $11-13$ weeks in pregnancies delivering small for gestational age neonates. Fetal Diagn Ther 2012;31(02): 103-108. Doi: 10.1159/000333810

53 Gernand AD, Simhan HN, Caritis S, Bodnar LM. Maternal vitamin D status and small-for-gestational-age offspring in women at high risk for preeclampsia. Obstet Gynecol 2014;123(01):40-48. Doi: 10.1097/AOG.0000000000000049

54 Kiely ME, Zhang JY, Kinsella M, Khashan AS, Kenny LC. Vitamin D status is associated with uteroplacental dysfunction indicated by pre-eclampsia and small-for-gestational-age birth in a large prospective pregnancy cohort in Ireland with low vitamin D status. Am J Clin Nutr 2016;104(02):354-361. Doi: 10.3945/ ajcn.116.130419

55 Hemmingway A, Kenny LC, Malvisi L, Kiely ME. Exploring the concept of functional vitamin D deficiency in pregnancy: impact of the interaction between 25-hydroxyvitamin $\mathrm{D}$ and parathyroid hormone on perinatal outcomes. Am J Clin Nutr 2018;108(04): 821-829. Doi: 10.1093/ajcn/nqy150

56 Cosmi E, Visentin S, Favretto D, et al. Selective intrauterine growth restriction in monochorionic twin pregnancies: markers of endothelial damage and metabolomic profile. Twin Res Hum Genet 2013;16(04):816-826. Doi: 10.1017/thg. 2013.33

57 World Health Organization. Guideline: Daily Iron and Folic Acid Supplementation in Pregnant Women. Geneva: WHO; 2012

58 van Eijsden M, Smits LJ, van der Wal MF, Bonsel GJ. Association between short interpregnancy intervals and term birth weight: the role of folate depletion. Am J Clin Nutr 2008;88(01):147-153. Doi: 10.1093/ajen/88.1.147

59 Hodgetts VA, Morris RK, Francis A, Gardosi J, Ismail KM. Effectiveness of folic acid supplementation in pregnancy on reducing the risk of small-for-gestational age neonates: a population study, 
systematic review and meta-analysis. BJOG 2015;122(04): 478-490. Doi: 10.1111/1471-0528.13202

60 Ding YX, Cui H. Integrated analysis of genome-wide DNA methylation and gene expression data provide a regulatory network in intrauterine growth restriction. Life Sci 2017;179:60-65. Doi: 10.1016/j.lfs.2017.04.020

61 Bjørke-Jenssen A, Ueland PM, Bjørke-Monsen AL. Amniotic fluid arginine from gestational weeks 13 to 15 is a predictor of birth weight, length, and head circumference. Nutrients 2017;9(12): E1357. Doi: 10.3390/nu9121357

62 Chen J, Gong X, Chen P, Luo K, Zhang X. Effect of L-arginine and sildenafil citrate on intrauterine growth restriction fetuses: a meta-analysis. BMC Pregnancy Childbirth 2016;16:225. Doi: 10.1186/s12884-016-1009-6
63 Bauchart-Thevret C, Cui L, Wu G, Burrin DG. Arginineinduced stimulation of protein synthesis and survival in IPECJ2 cells is mediated by mTOR but not nitric oxide. Am J Physiol Endocrinol Metab 2010;299(06):E899-E909. Doi: 10.1152/ ajpendo.00068.2010

64 von Elm E, Altman DG, Egger M, Pocock SJ, Gøtzsche PC, Vandenbroucke JP; STROBE Initiative. The Strengthening the Reporting of Observational Studies in Epidemiology (STROBE) statement: guidelines for reporting observational studies. J Clin Epidemiol 2008;61(04):344-349. Doi: 10.1016/j.jclinepi.2007.11.008

65 Goodacre R, Broadhurst D, Smilde AK, et al. Proposed minimum reporting standards for data analysis in metabolomics. Metabolomics 2007;3(03):231-241. Doi: 10.1007/s11306-0070081-3 